\title{
Metallic Additive Manufacturing: Design, Process, and Post-Processing
}

\author{
Ian Gibson 1,2,*(D) and Amir Mahyar Khorasani ${ }^{1, *}$ \\ 1 School of Engineering, Faculty of Science, Engineering and Built Environment, Deakin University, \\ Victoria 3216, Australia \\ 2 Industrial Engineering, Dept. Design, Production \& Management, University of Twente, 7522 NB Enschede, \\ The Netherlands \\ * Correspondence: ian.gibson@deakin.edu.au (I.G.); a.khorasani@deakin.edu.au (A.M.K.)
}

Received: 16 January 2019; Accepted: 22 January 2019; Published: 27 January 2019

The first modern additive manufacturing machines, developed in the early 1990s, primarily made parts using polymers. Such parts were generally inaccurate with poor mechanical properties. Fast-forward to today and we see huge improvements in all aspects of the technology with the added benefit of significantly reduced costs. Furthermore, the range of materials has broadened to include composites, ceramics, and of course metals. It came as no real surprise when Metals journal approached us to oversee a Special Issue on the topic of Metallic Additive Manufacturing. Recently a number of front running companies have made major headlines in the use of metal additive manufacturing for direct production of parts to be used in medical, automotive, and even aeronautical applications. Most notable of these is GE, who have included functional metallic AM parts in their latest jet engines. The company has such faith in AM technology that they acquired two major metal AM equipment providers and established a new company vertical called GE Additive.

Industry generally uses metals when they require superior mechanical properties like tensile strength, heat resistance, and high accuracy with low tolerance. This final requirement has always been a problem for metal AM technology with most machines providing a surface finish of a few tens of microns at best. For many applications this is simply not good enough and so additional post-AM process stages are often necessary. Such stages include heat treatment, machine finishing, and coatings. It is becoming increasingly clear that, particularly where metal AM is concerned, there is still a need to include process planning at the product design stage. The technology is therefore not set to replace conventional manufacturing as many have previously suggested, but rather provides additional scope to enhance manufacturing.

To make the best use of AM technology, we must study it carefully. Applications research facilities like the newly established Fraunhofer Project Centre at the University of Twente in The Netherlands, which both editors are affiliated with, aim to introduce new technologies like metallic AM to manufacturers so that they can best understand how it is set to change their products and processes for the better. To do so, researchers must study and understand what others are doing around the world, hence the need for initiatives like this Special Issue.

In the four papers that have completed the rigorous review process for the journal, you will note that there is a heavy emphasis on applications. The paper by Cortina et al. [1] explicitly looks at how metal AM can improve hot stamping through the use of conformal cooling, something that is very difficult to produce with conventional manufacturing. The papers by Lieberwirth et al. [2] (on composite metallic extrusion based AM) and Segura-Cardenas et al. [3] (on the permeability of powder-bed fusion AM fabricated parts) are both analytical studies on what properties we can expect from metal AM technology. The final submission by Hu et al. [4] discusses a technique for improving or changing the functionality of metal AM parts using cryogenic treatment. All of these papers are 
of a high standard and well worth reading if you are studying the corresponding areas. We hope you appreciate the papers in this Special Issue and further hope that they encourage you to help in improving this understanding within your own research.

Conflicts of Interest: The authors declare no conflict of interest.

\section{References}

1. Cortina, M.; Arrizubieta, J.I.; Calleja, A.; Ukar, E.; Alberdi, A. Case Study to Illustrate the Potential of Conformal Cooling Channels for Hot Stamping Dies Manufactured Using Hybrid Process of Laser Metal Deposition (LMD) and Milling. Metals 2018, 8, 102. [CrossRef]

2. Lieberwirth, C.; Sarhan, M.; Seitz, H. Mechanical Properties of Stainless-Steel Structures Fabricated by Composite Extrusion Modelling. Metals 2018, 8, 84. [CrossRef]

3. Segura-Cardenas, E.; Ramirez-Cedillo, E.G.; Sandoval-Robles, J.A.; Ruiz-Huerta, L.; Caballero-Ruiz, A.; Siller, H.R. Permeability Study of Austenitic Stainless Steel Surfaces Produced by Selective Laser Melting. Metals 2017, 7, 521. [CrossRef]

4. Hu, Z.; Zheng, H.; Liu, G.; Wu, H. Effects of Cryogenic Treatment after Annealing of Ti-6Al-4V Alloy Sheet on Its Formability at Room Temperature. Metals 2018, 8, 295. [CrossRef]

(C) 2019 by the authors. Licensee MDPI, Basel, Switzerland. This article is an open access article distributed under the terms and conditions of the Creative Commons Attribution (CC BY) license (http:/ / creativecommons.org/licenses/by/4.0/). 